\title{
Not what you know, nor who you know, but who you know already: examining online information sharing behaviours in a blogging environment through the lens of social exchange theory
}

[Manuscript accepted for publication in Libri 60]

By Hazel Hall, Gunilla Widén, and Lorraine Paterson

This article is based in part on the paper "Shared relationships, spaces and online information behaviours: a social exchange and capital perspective" presented at the international conference " $\mathrm{i}$ ': Information: Interactions and Impact', organised by the Robert Gordon University's Department of Information Management, and held in Aberdeen, Scotland, 22-25 June 2009.

Dr Hazel Hall, Director - Centre for Social Informatics, School of Computing, Edinburgh Napier University, Edinburgh, Scotland

Email:h.hall@napier.ac.uk

Dr. Gunilla Widén, Professor, Information Studies, School of Business and Economics, Åbo Akademi University, Turku, Finland

Email: gunilla.widen-wulff@abo.fi

Lorraine Paterson, Usability analyst/developer, Information Technology and Services, University of Edinburgh, Edinburgh, Scotland

Email: 1.paterson@nesc.ac.uk

\section{Abstract}

This paper focuses on the extent to which online information sharing practice is socially motivated. A key interest is how knowledge of the existing social connections between actors may predict their information sharing behaviour when they move into an online environment, and the relative importance of these connections when set against other factors that may motivate online information sharing within a closed group. The examination of online information exchanges between members of a defined community of bloggers reveals that those with established off-line relationships are more likely to interact with one another when they move into an online environment than those who have not enjoyed earlier contact. The findings of the empirical study are evaluated with reference 
to social exchange theory, with acknowledgement of the importance of shared social capital as a prerequisite for the efficient operation of work-groups, both in face-to-face and online environments. It is concluded that social exchange theory can be deployed as a means of explaining online information sharing behaviours. The study findings have implications for the design of environments for purposes of online information sharing, especially in terms of the provision of substitutes for physical proximity in distributed organisations, the operation of reward systems, and expectations for communities to develop their own information sharing ecologies.

\section{Introduction: accounting for engagement in information sharing in online environments}

The study reported in this paper germinated from an observation that student members of an online community appeared to replicate their classroom levels of interaction with one another in the blogging environment created for them to extend discussion of module content outside class time. The research project was thus first initiated to test whether this really was the case and, if so, to consider the influence of existing social relationships on information exchanges within the online environment. Aligned with this, the determinants of the existing relationships were of interest. It was anticipated that the outcome of the work might help the module tutors to develop strategies to encourage a greater level of interaction across all students taking the module in future deliveries, and to ensure that online conversations related to the study topics were broadened to include contributors beyond just small cliques of friends. Thus the full range of both strongly and weakly-tied individuals in the class would be encouraged to contribute to discussions, the quality of which - it was hoped - would improve with greater variety of input. From a broader perspective it was also recognised that the majority of graduates should expect to work collaboratively over distances in their future careers, whether this be for a large distributed organisation or for a smaller one that deals with a number of external partners. As such, it made sense to create the conditions where students felt confident to risk interaction with strangers in this closed environment as preparation for the entry into the workplace.

Given the strong indication that social relationships were key to how students chose to make their contributions to the online community in question, the main tenants of social exchange theory provided a framework for the study. This, it was felt, would help make sense of the information sharing activities in this particular online environment. In addition, it was hoped that a contribution could be made to the growing literature base on social exchange theory as applied to information sharing. Although social exchange theory has been adopted by other researchers in recent years for such purposes, Liang, Liu and $\mathrm{Wu}$ (2008) have noted that the findings of these studies have been inconsistent, and thus lead to problems of interpretation from the perspectives of both theory 
development and advice for practical implementations. There was therefore scope to help address these issues.

An overview of social exchange theory provides the starting point for this paper. Then follows an account of the design and implementation of the empirical study. Next the findings of the investigation are related with reference to the influence of (1) established off-line relationships, (2) rewards, and (3) the developing information sharing ecology on information sharing practice. From this analysis it is concluded that social exchange theory can be deployed as a means of explaining online information sharing behaviours. This has implications for the design of environments for purposes of online information sharing, especially in terms of the provision of substitutes for physical proximity in distributed organisations, the operation of reward systems, and expectations for communities to develop their own information sharing ecologies.

\section{Literature review: Exchange theory, social exchange theory, social capital and studies of information sharing}

This study considers social exchange theory as an explanatory factor of online information sharing behaviour, as proposed by Hall (2003). Social exchange theory is developed from exchange theory. Exchange theory, which derives from economics, argues that resources are bought and sold in deals subject to contractual obligations, where resources are exchanged for currency. Purchasers make their choice from a range of options, and normally select the goods that offer the best value for the lowest cost. In an exchange economy the initiations that produce the greatest value increase in frequency. Social exchange theory is regarded as a "flavour" of exchange theory. Here "resources" are "bought" and "sold", but the mutual obligations of the trading partners are ill-defined. Any "deals" concluded are not necessarily subject to contractual obligations, nor are "resources" necessarily exchanged for currency. In addition, the "resources" exchanged may be valued more highly than their market cost. A social exchange relationship differs from one based on straightforward exchange because the actors involved share social bonds, enjoy high levels of mutual trust, and operate within long-term co-dependent relationships. Since the early twentieth century economic anthropologists have discussed systems of social exchange of physical artefacts as "gift" economies. They argue that rituals of gift giving provide insight on group values and behaviours such as the mutual regard and respect of parties who participate in the exchange (Hall, 2003, pp. 290-291).

Social exchange theory has been applied in research in a wide range of academic domains, for example: in archaeology to explain the discovery of non-indigenous materials distant from their site of manufacture (McNiven, 1998); in sociology to examine power relationships (e.g. Janssen, 2000); and in information systems with reference to the successful operation of open source software communities (e.g. Bergquist and Ljungberg, 2001). A number of more recent studies consider social exchange theory and information and knowledge sharing together (e.g. Bock and Kim, 2002; Cabrera 
and Cabrera, 2005; Johnson and Faraj, 2005; Kankanhalli, Tan and Wei, 2005; Wu, Lin and Lin, 2006; Watson and Hewett, 2006). The most recent comprehensive review of the literature direct relevance to this article is the meta-analysis presented by Liang et al (2008).

Social exchange theory has also been deployed to a limited extent in information science. For example: in The scholar's courtesy, Cronin (1995) demonstrated how the expectation of exchange motivates collaborative working in research environments (p. 7) and identified acknowledgements in journal articles as gifts exchanged in recognition of earlier gifts of help (p. 18); Sawyer, Eschenfelder and Heckman (2000) made direct reference to social exchange theory in their study of knowledge sharing across distributed computing support staff at a university; Hall (2003) proposed the value of social exchange theory as a means of explaining the willingness of actors to share information and knowledge in knowledge markets; and Willem, Scarbrough and Buelens (2008) have more recently treated social capital and social identity as a form of social exchange in their paper on knowledge integration.

The broader theme of social capital, which focuses on social structures and relations, has been studied in many online settings, such as virtual learning communities (e.g. Daniel, Schwier and McCalla, 2003) and social networking sites (e.g. Ellison, Steinfield and Lampe, 2007). Findings from these studies reveal that the boundaries that previously distinguished real from virtual space are fading as social actors move more frequently within and among different domains (Malaby, 2006). In the online space feedback mechanisms and regulatory practice are important artefacts that facilitate the formation of social capital, which in turn motivates contributions (Law and Chang, 2008). For example, a study of multiplayer online gamers showed how players grow different kinds of social networks in a game where rules, boundaries, and norms are formed. Here social capital is created as players group into these social networks for different purposes. For players who know each other prior to the online game, this is an important way to maintain and pursue their relationships. For others it provides an opportunity to develop bridging social capital (Williams, et al., 2006). The motivations to share in the context of social media are often connected to a strong culture of reciprocity. This is visible, for example, in Flickr, a popular photo sharing site, where members anticipate comments on their photographs from others with the expectation of a comment on theirs in return, or at least a thank you for the comments. Interactivity, belonging, and individual creativity are also incentives for participation mentioned in this context (Cox, Clough and Marlow 2008).

The findings of the empirical study discussed in this paper (elaborated below) are evaluated with reference to social exchange theory, with acknowledgement of the importance of shared social capital as a prerequisite for the efficient operation of work-groups, both in face-to-face and online environments. 


\section{Exploration of the Information Delivery blogosphere: design of the empirical study}

\section{Site of data collection}

The research findings presented here are based on the analysis of data sets from two blogging communities made up of student members. These communities comprised students only: the tutors did not participate. The data were collected from third year undergraduates who took a module entitled "Information Delivery" in the School of Computing at Edinburgh Napier University in 2007 and 2008. The module itself was concerned with the analysis of, and solutions to, organisational information delivery problems. Curriculum topics included, for example, causes and means of avoiding institutional information overload, the proliferation of in-house islands of automation, and how to tailor information delivery for particular end-user audiences.

At the time that this module was presented the majority of School of Computing students in the full third year cohort were undertaking industrial placements. This module was one of a set designed for the students completing the third year of their undergraduate studies on campus rather than in the workplace as placement students. The set of on-campus modules was intended to act as a placement "proxy" as far as was possible. The full range of programmes offered in the School of Computing was represented in the module cohort, for example Information Systems, Internet Computing, Multimedia, Networking, Human Computer Systems, and Software Engineering. In addition, a high proportion of class members were international students: for example, in the 2008 cohort $48 \%$ were non-native English speakers. Thus the full cohort was diverse, both in terms of academic subject interests and nationality.

The learning environment for this module has developed since it was first offered in 2004. For its first delivery students kept closed learning logs as word-processed files. In these they were asked to reflect on their weekly experiences of the class reading, lectures and lab activities. In 2005 and 2006 a bespoke blogging environment internal to the module was set up for the students, thus moving the students' weekly entries from private space into one that was more public [1]. This, it was felt, would widen opportunities for collective learning through three main activities:

1. "speaking out" through the creation of blog entries;

2. "listening" through the reading the entries of other students;

3. "discussing" by commenting on the blog entries of others, and receiving comments from others on one's own work.

In 2007 the "portfolio" function of WebCT was adopted as the environment in which students shared information about their studies on the module. As part of Edinburgh Napier virtual learning 
environment, it is possible for the portfolios in WebCT to be viewed by any Edinburgh Napier user granted permission by the portfolio owner. Thus from onwards 2007 students on the module were able to invite others from outside the class to read and comment on their work for the Information Delivery module, should they wish to do so.

In 2007 and $200870 \%$ of the course assessment marks for the module was allocated to the blog entries and comments (with the remaining 30\% allocated to a written team report). The requirements for the weekly main entries were that they should:

1. be relevant to that week's module content;

2. make links between theory (from the set reading and the lecture) and practice (from the lab exercises);

3. demonstrate understanding or highlight areas of difficulty;

4. justify points made through reasoned argument by, for example, referring to the reading material or citing personal experience.

The requirement for the comments was that they should either (a) extend the line of argument of the original blog postings, or (b) offer alternative views. Each student was required to contribute at least two comments per week.

This closed community of bloggers served as the site for data collection for this study. It was anticipated that data collected and analysed would provide insight into how existing social connections between actors might be used to predict information sharing behaviour in online environments. It would also be possible to test the relative importance of other factors that motivate online information sharing within the defined group.

\section{Data sources for the study}

There were four main sources of data for the study:

1. Main blog entries on WebCT: the main blog entries were examined for reflections on information sharing in this environment, and stated motivations for participation.

2. Comments on the main blog entries: the comments were examined for any mention of information sharing practice in the learning environment, and the patterns of commenting interaction between actors were noted.

3. Student tie data: the students completed a social cohesion survey [2] which took the form of a simple grid of names. The completed surveys gave an indication of the familiarity of student pair members at the start of the module. For each named member of the class listed on the survey sheet students were asked to identify whether they knew each person in the class "well", "a little" or "not at all".

4. University records: for each class member details of the degree programme, tutorial group for the module, as well as team membership details for the group course work assessment for the module were gathered. This data indicated the "official" proximity (in University terms) of individual students to one another. 
Additional interview data were also collected from the 2007 cohort.

The data were analysed to examine the possible influences on online information exchanges between members of the class. A mixed approach to data analysis was adopted. The influence of existing relationships was examined through a quantitative analysis of the student tie pairs identified in the social cohesion survey data (595 pairs from 35 students in 2007, and 351 pairs from 27 students in 2008), and the patterns of exchange between student pairs. Statements made in the main blog entries and comments, supplemented by interview data, revealed apparent attitudes to both hard/explicit and soft rewards (as defined by Hall, 2001) for information sharing online in this environment. These statements also pointed to the extent to which a desire to reciprocate motivated online exchanges. A combination of student statements from the online environment and interviews plus commenting patterns gave an indication of the ecology of the online environment and its influence on online information sharing behaviours.

\section{Suitability of the design and implementation of the empirical study}

The output of the efforts of research design for the empirical work described here has resulted in a case study based on two data sets. As such, it is open to the general criticisms regularly levelled at case study research, such as questions as to the extent to which its findings may be generalisable. However, generalisability was not a goal of the study: the power of organisational context on technology tool adoption in general is well-recognised (Ciborra, 2002), and information and knowledge sharing practice in particular has been shown to be context-dependent (for example, Hall and Goody, 2007; Liang et al., 2008). Moreover, the goal of the study was not intended to shape new hypotheses, but instead to provide an explanation of what was observed in the environment studied and - as such - the methods deployed allowed this to be achieved, as will be evident in section 4 below.

The main strategies employed to gather and analyse data for this study drew on established practice in social research. In some cases, however, conventions were adapted. For example the means by which statements on motivations to contribute to other students' work that were extracted from the main blog entries and comments and analysed might be described as a form of content analysis. However, it would be an exaggeration to say that the study was a content analysis per se in the strictest sense of the term (as noted, for example, by Denscombe, 1998, pp. 167-168). This is because - for the purposes of this research - it was only necessary to analyse the material of direct relevance to the study's themes from all the correspondence available in the blogging environment.

Further compromises were determined by factors that were beyond the control of the project team. For example, in 2007 the project work was started within a couple of weeks of the students completing the module. It was therefore possible to recruit interviewees quickly before the students left the university at the end of the 2006/7 academic year. In contrast, in 2008 work on the project did not start 
until a few months after the module had been delivered. By the time that the data collection process started on the 2008 data it was the autumn, and the students who had taken the module were not available for interview.

A further issue worthy of discussion is the credibility of the data sources on which the report of this study is based. Whenever data are collected directly from data subjects there are concerns as to the "truthfulness" of responses. In this study three of the four main data sets analysed derived from students who were undertaking a module for credit in an environment that some may regard as "fake". For example, the requirement for students to make two comments a week resulted in a quantity of online traffic that does not replicate the lower levels of interaction in a "real" world blogging environment. An obvious risk to this study is that its findings might be based on data supplied by students who were motivated to express what they perceived to be "right" in the eyes of their tutors, rather than to record their genuine thoughts. It should be noted, however, that when the students wrote their blog entries and comments they did not anticipate future scrutiny of their work for research purposes. Thus the material assembled into data sets (1) and (2) (as listed above) derived from artefacts of the community under study and, as such, have authenticity and credibility as a rich data source (Silverman, 1993, p. 89). Nevertheless, it was still recognised that the students' contributions to the blogging environment were socially produced, and the objectivity of what was said there cannot be guaranteed.

Data sets (3) and (4) pose their own particular problems. In the case of the social cohesion survey, i.e. data set (3), a single individual's assessment of acquaintance with another may not match the view of the other pair member. For this reason, only pairs where both students agreed their level of acquaintance were included in the sample for analysis. Even data set (4), which intended to measure student "proximity" is subject to criticism. Whilst it was comprehensive in providing proximity data from University records, it could not encompass much "informal" proximity such as details of students who shared the same flat, travelled to the University for classes together each day, had attended the same high school etc. More extensive data collection through the deployment of social network analysis would have provided a stronger basis for conclusions on the proximity of students to one another, as well as measured other features of the classes as networks in terms of their size, reachability and density, and the centrality of key actors. A genuine social network analysis would have furnished a stronger sense of each cohort as a group (rather than as sets of pairs). This technique may also have made it possible to see other network features, for example how the social structure of the blogging environment grew through individual action, or how the social structure influenced individual and collective action.

Taking into account the limitations discussed above, the analysis of the data produced some valuable results, and these are outlined below. 


\section{Findings from the empirical study}

\section{The influence of established off-line relationships on online information exchange}

It is noted above that the student cohort under consideration was diverse: effectively the classes comprised several small sets of students from a wide range of degree programmes, who had elected not to join the majority of the year group on industrial placement. A large number of class members were international students, some of whom were not able to go on placement due to the terms of their international student status. The student cohesion surveys revealed that where the students provided matching relationship status detail (i.e. each student had independently gave the same response as to whether they knew the other student "well", "a little" or "not at all") just 62 (11\% of the total of 946 student pairs) considered themselves to be well-acquainted.

The data analysed from the social cohesion survey and discussed below derives from all 62 "friend" pairs (i.e. pairs where both students had marked on the survey "I know this person... well"), and all 29 agreed "acquaintances" ("I know this person... a little"). A sample of 63 "stranger" pairs (where both students had declared "I know this person... not at all") provided the remainder of data for analysis. The main blog entries and comments of each of the 154 pairs were examined for evidence of patterns of reciprocated commenting practice. As can be seen from Table 1 below, across the entire sample set there was little evidence of reciprocation. For example, for each set of pair categories the majority exhibited no reciprocation at all. Most reciprocation is evident between friends and the least is seen between strangers. The best hope of online information sharing for a stranger pair in this environment was a single reciprocated exchange.

Table 1: Relationships and reciprocated commenting practice in agreed pairs

\begin{tabular}{|l|l|l|l|l|l|}
\hline Pairs & $\begin{array}{l}\text { No } \\
\text { reciprocation }\end{array}$ & $\begin{array}{l}\text { A little } \\
\text { reciprocation }\end{array}$ & $\begin{array}{l}\text { Some } \\
\text { reciprocation }\end{array}$ & $\begin{array}{l}\text { Much } \\
\text { reciprocation }\end{array}$ & Total \\
\hline $\begin{array}{l}\text { Friend } \\
\text { N=62 }\end{array}$ & $39 \%$ & $29 \%$ & $3 \%$ & $29 \%$ & $100 \%$ \\
\hline $\begin{array}{l}\text { Acquaintance } \\
\text { N=29 }\end{array}$ & $86 \%$ & $4 \%$ & $10 \%$ & & $100 \%$ \\
\hline $\begin{array}{l}\text { Stranger } \\
\text { N=63 }\end{array}$ & $95 \%$ & $5 \%$ & & $100 \%$ \\
\hline Key & $\begin{array}{l}\text { Student A comments on Student B's work and Student B comments } \\
\text { on Students A's work. }\end{array}$ \\
\hline A little reciprocation & & & \\
\hline
\end{tabular}




\begin{tabular}{|l|l|}
\hline Some reciprocation & $\begin{array}{l}\text { A pattern of commenting between Student A and Student B is } \\
\text { evident. }\end{array}$ \\
\hline Much reciprocation & $\begin{array}{l}\text { A strong pattern of commenting between Student A and Student B is } \\
\text { evident. }\end{array}$ \\
\hline
\end{tabular}

The quantitative data collected from the social cohesion survey and analysed with the patterns of commenting practice thus indicate that reciprocated information sharing in online environments is more prevalent amongst those who have existing off-line relationships. Further evidence of this was found in statements that students made about their commenting practice, some of which offered explanations for this behaviour, for example:

"The only comments I have received are from people that I know and I think it is the same for other students. I do the same as well."

"In the first week I posted comments only to [my friends'] blogs to get comments from them on my own blog."

"The majority of the time, my comments gravitated towards the logs of my friends if only because I was armed with the knowledge that they knew me and would not take anything I wrote the wrong way."

“... it is so much easier to comment on my friends' blogs since I understand their thinking better."

These findings align neatly with the outcomes of previous work that has concluded that bloggers tend to direct their output deliberately to others with whom they have strong ties (Stefanone and Jang, 2008). This practice tallies with an expectation that members of this particular audience should comment on the blogger's output. Equally the sense of the blogger's own obligation to return the favour is also strong.

The proximity data was analysed to explore relationships between degree programme and class memberships, and then matched against online commenting practice. 18 friend pairs exhibited high levels of reciprocated online information sharing (represented in the figure of $29 \%$ in Table 1 above): 10 from the 2007 cohort and 8 from 2008. All the pair members from 2007 shared the same degree programme and attended the same lab session for the Information Delivery class, and in some cases were assigned to the same course work teams for the group assessment. Similarly in 2008 of the eight pairs five shared the same degree programme. Of the remaining three, two had regular contact as members of the same lab session for the Information Delivery class. Just one pair had no obvious class contact. Table 2 below shows that the majority of pairs that demonstrated high levels of reciprocation 
comprised members who shared the same degree programme. The analysis of the "proximity" data forms a basis for the extension of the argument above that those in pre-existing off-line social relationships are more likely to information share in online environments. Here there is also a strong indication that proximity makes it possible for off-line friendships to be established in the first place. These finding aligns with those of previous studies of information sharing with reference to social exchange theory that have concluded that social interaction is a pre-requisite to such activity (e.g. Chiu, Hsu and Wang, 2006). They also have parallels with the outcomes of studies that report a lower likelihood of 'newbies' receiving help with queries posted to message boards, when compared with requests from established community members (e.g. Arguello, et al., 2006).

Table 2: Degree programme "proximity" and high reciprocation pairs

\begin{tabular}{|l|l|l|}
\hline $\begin{array}{l}\text { Are members of this high reciprocation pair on } \\
\text { the same degree programme? }\end{array}$ & 2007 students & 2008 students \\
\hline Yes & $70 \%$ & $62.5 \%$ \\
\hline No & $30 \%$ & $37.5 \%$ \\
\hline Totals & $100 \%$ & $100 \%$ \\
\hline
\end{tabular}

\section{The influence of rewards on online information exchange}

In the main blog entries and comments the students expressed their attitudes to the rewards on offer for contributing to the discussions in the blogging environment. As has been identified in previous studies (e.g. Matzat, 2007; Tiwana and Bush, 2005) the soft social reward of the approval of work completed was sought by many students, as illustrated in the quotations below:

"...comments can be very useful to motivate the blog's author. Without comments a blog's author can have the impression that his work is useless because it interests nobody."

“I don't like not getting any comments - makes me feel like my blog wasn't good enough to comment on."

In some cases, students associated receipt of comments with reputation enhancement:

"Receiving a comment almost acts as a seal of approval. It was rewarding to know that the blog had actually been read by someone [and] the time and effort to write the blog entries had been worthwhile."

"We were aware that everyone was meant to comment on another two blog entries. Therefore you didn't want to be seen as the one who had been left out, or less popular..." 
The decision that the module tutors would not participate as active, visible members of the class in the online environment was made on the basis that the conversation should be student-owned and driven. The tutors did, however, offer class feedback on blogging practice at the start of the module in the lecture hall. It was considered possible that in highlighting particular student blog entries as examples of good practice the tutors might have encouraged class members to address future comments to the owners of the "favoured" blogs. To test this, an examination was made of commenting patterns as relevant to the publicly-acknowledged blogs in the weeks following their mention. The analysis showed that the fact that tutors had referred to the work of particular students at a certain point in the module did not boost the number of comments received in subsequent weeks: tutor attention had no pronounced effect on the number of comments any blog entry attracted. This points to the conclusion that the social reward of approval of work may be more valued when it derives from peer members of the community, rather than from an outside observer. This suggestion, however, needs to be treated with caution. For example, in 2008 the work of almost half the student cohort was publicly highlighted by the tutors, and mention was for a variety of reasons, including humour and playfulness in the entries. The mentions were also limited to the second and third weeks of the trimester, so together these factors render it difficult to judge the potential impact of more explicit tutor intervention over a longer period.

It is also worth considering the impact of the hard reward of marks as an incentive for contributions in the online environment. In this case the obvious hard reward was the $70 \%$ allocation of course work marks to the blogging activity. Statements made in the main blog entries provide an indication of three levels of participation in exchange for a grade. A few students admitted to making a minimal effort for the sole purpose of gaining a course work mark that would contribute to a pass. They were blunt in their admissions. For example, one said "I definitely don't think that I would have created the blogs and posted comments had it not been part of the course work specification", and another confessed "What motivated me... to be perfectly honest, the fact that I'd fail if I did not do the commenting". The second category comprised a set of students who participated well but always with an eye on the level of work required to achieve a good mark. The largest group, however, was made up of those who, although conscious that their work would attract a grade at the end of the trimester, made a considerable effort to discuss their work in the online space. The participation of this majority, who exceeded the bare requirements of the course work specification in their online interactions, clearly regarded that their blogging and commenting activities were worth more than the official reward of a mark for the course work. It can be concluded that the hard reward of the mark did serve to motivate students to share information in this environment, but not as obviously as the social rewards associated with peer approval and reputation enhancement. 


\section{The influence of the developing information sharing ecology}

From remarks made by the students in their online contributions and an examination of commenting practice, it is possible to see how an online community develops its own information sharing ecologies over time. In both cases described here (i.e. the 2007 and 2008 deliveries of the module) there was evidence to suggest that as the students became more familiar with the environment and one another they began to consider taking greater "risks" with their contributions. For example, they were more likely to comment on a "stranger's" blog entry at the end of the module than they were at the start, and the comments contributed in the later stages of the module were more challenging. Indeed, by the end of the module some students remarked that they wished that they had been bolder in their blogging and comments from the start, not least to raise the level of online debate. For example, one student wrote:

"[At the start] I had read a blog or two, started to comment then changed my mind as I was being rather mean... Now I wish I had continued writing the comments, maybe softening the blow... It could have helped them."

Furthermore there was evidence that in the case of both data sets that the blogging environments were beginning to develop into gift economies (Mauss, 1925/1990) by the end of the module. Some of the students demonstrated awareness of this in their blog entries on commenting practice:

“... as I went on, I started to comment on people who had commented on my posts...”

"One thing I do feel when someone comments on my blog [is] obliged... to comment on theirs."

"I am a bit disappointed with the turn-out of comments on my blog site as I tried to harass people to post comments, but I guess it didn't work... If I posted more on other people's blogs, perhaps I would have gotten more comments?"

These observations relate to the context of the blogging environment of the module as a social space for learning. Here the blogosphere itself provides scaffold for social infrastructure amongst the membership in terms of (1) support for discussion, feedback and learning, (2) a safe environment in which to challenge and reflect on the "realities" of the subjects studied over the course of the module, (3) a place in which the community could "meet". This was first identified from when the initial blogging environment created for the module in 2005 was reviewed (Hall and Davison, 2007).

\section{Review of the findings of the empirical study and conclusions}


This study demonstrates that where off-line relationships exist between pairs of actors prior to entry into an environment set up for online information exchanges, the likelihood of these pairs maintaining their relationship online is much greater than the possibility of two acquaintances or strangers sharing information. To a certain extent, some of the students in this environment appeared to use it as a medium for interpersonal communication between friends, rather than a tool of group communication with all members of the class. In addition, it indicates that social rewards such as approval of the quality of work and validation of an individual's membership of the group are important. These are in the gift of the community, and are more powerful as incentives for participation than any hard rewards on offer (which, in this case, was a mark for the work completed in the gift of community outsiders in the person of the module tutors). There is also some evidence to suggest that as the ecology of an online environment develops, the desire to reciprocate contact grows amongst participants as they "learn" this mode of behaviour. In this case it is suggested that a gift economy may have emerged more strongly had the duration of the module extended beyond a single trimester.

It is also important to note that the pre-condition for the existing relationships that can then flourish in the online environment is proximity. Proximity provides opportunities for relationships to develop, and it is these relationships that endure in the online environment through heightened information exchange. These findings contribute to understanding of the types of relationships that condition information flow in networks, an area that has been under-researched to date, as noted by a number of commentators (e.g. Borgatti and Cross, 2003; Huysman and Wulf, 2006).

It is possible to draw on the main findings of the study to test the applicability of social exchange theory to information sharing in online environments. Some students clearly "deal" in information through trading information exchanges, as shown in the relationships with a high degree of reciprocation of comments. These interactions, however, only exist between established student pair members, thus indicating that this level of exchange depends on shared social bonds and mutual trust in relationships that are expected to endure. The social capital shared between pair members provides both the structure for the exchanges to take place, and the conduit along which information flows. When the whole blogging environment is considered as a developing ecology the findings of the study recall some of the early theoretical work on social exchange theory, such as Blau's identification of how a "spiral of trust" (Blau, 1964, p. 71) is generated amongst actors over time. As well as these findings being of interest at a local level, an understanding of the relevance of the main tenets of social exchange theory to information sharing in online environments is important to organisations which seek to equip teams for new knowledge creation, an output that depends on exchange alongside combination as one of its two key processes (Nahapiet and Ghoshal, 1998).

As has been noted above, however, this is a single case study that considers an activity that is highly context-dependent and - as such - the detail of its findings may not be applicable to other environments. For example, all participants in this blogging environment were of equal status as 
students, with only one identifiable "hard" reward on offer for participation, i.e. the grade. Whether social factors would emerge as such a strong influence in a work-based blogging community of workers at different levels in a hierarchical organisation where contributions might be rewarded in a variety of ways (including financially) is open to debate. Nevertheless, together with other research output on incentives to share information in online environments (e.g. Cabrera, Collins and Salgado, 2006; Hsu and Lin, 2008; Lakhani and von Hippel, 2003; Wasko and Faraj, 2005) it is the contention of this study that social reward is key.

Thus a number of implications present themselves to those who seek business benefits from interactions in online communities, particularly if these communities are set up across geographies in an attempt to compensate for low opportunities for physical proximity. Attention needs to be directed towards how dialogues can be engineered across a broad range of contacts where opportunities for physical co-location are minimal, and/or proxies for co-location devised. Equally when new environments for online information sharing are introduced to a user-base time needs to be allowed for the participants to become familiar with the tools and feel confident enough to take perceived risks with their contributions.

The work presented here could be extended further to test the applicability of its findings in other settings, such as within business. In terms of methodological approach, aspects examined could be scrutinised more closely in future work. For instance, a more rigorous means of identifying social links between the actors, such as social network analysis, might offer additional insight, for example in highlighting which type of social link is the most influential in securing relationships on which information sharing practice can be built. In addition, other data sources generated in the online space could be examined. For example, exchange theory states that initiations that produce the greatest value increase in frequency. Taking this into account, a detailed examination of online traffic flow in the community would be worth consideration. This approach would also present the opportunity to extend the study to consider the degree of generalised (as opposed to direct) exchange in this environment, i.e. the cases where more than two actors are involved in the exchange relationship and reciprocal dependence is indirect.

It is also worth noting here that a parallel piece of work based on analysis of some of the data collected for this study is currently in progress. Having examined commenting activity in the blogging community through the lens of social exchange theory, work is underway to explore the relevance of social identity theory (Tajfel, 1982) in the same context. This is of particular interest due to the high proportion of international students on the Information Delivery module, and may explain the low number of friendship pairs - just $11 \%$ - identified for this study. The output of this second study is expected to reveal insight as to the extent to which these international students became integrated into the online conversations over time, and how affective ties with others in the class emerged. When completed the additional work will develop further themes explored in other studies in information science that have considered together social exchange theory, social identity theory and information 
sharing (e.g. Willem et al., 2008). Equally, the extended work may also produce findings on the degree to which social software may trigger social behaviour, and thus add to the extant literature on this topic (e.g. Bouman, et al., 2008).

\section{Acknowledgements}

The authors of this paper gratefully acknowledge the Carnegie Trust for the Universities of Scotland, Edinburgh Napier University, and the Åbo Akademi University for providing financial support for this study. We are also grateful to Brian Davison of Edinburgh Napier University, Scotland for his help in preparing the data for analysis in the empirical study.

\section{Notes}

1. This change and its impact are discussed in detail in Hall and Davison (2007).

2. The survey form was also used to obtain permission from the students to use their anonymised data in the reports of the research.

\section{References}

Arguello, J., B. Butler, E. Joyce, R. Kraut, KS. Ling, and X. Wang. 2006. Talk to me: foundations for successful individual-group interactions in online communities. In CHI 2006: Proceedings of the SIGCHI conference on Human Factors in computing systems, 22-28 April, Montreal, Canada. URL http://portal.acm.org/citation.cfm?id=1124772.1124916\&coll=GUIDE\&dl=GUIDE\&type=series\&idx $=$ SERIES260\&part $=$ series $\&$ WantType $=$ Proceedings $\&$ title $=$ CHI\&CFID $=66861195 \&$ CFTOKEN $=1549$ 5978 [viewed 6 April 2010]

Bergquist, M., and J. Ljungberg. 2001. The power of gifts: Organizing social relationships in open source communities. Information Systems Journa/ 11: 305-320.

Blau, P. 1964. Exchange and power in social life. New York: Wiley.

Bock, GW., and Y-G. Kim. 2002. Determinants of the individual's knowledge sharing behaviour: the theory of reasoned action perspective. Proceedings of the Pacific-Asia Conference on Information Systems (PAC/S) Proceedings, Tokyo, Japan, 2002, 1008-1023.

Borgatti, SP., and R. Cross. 2003. A relational view of information seeking and learning in social networks. Management Science 49(4): 432-445.

Bouman, W., T. Hoogenboom, R. Jansen, M. Schoondorp, B. de Bruin, and A. Huizing. 2008. The realm of sociality: notes on the design of social software. Sprouts Working Papers on Information Systems 8(1). URL - http://sprouts.aisnet.org/8-1 [viewed October 19, 2009].

Cabrera, EF., and A. Cabrera. 2005. Fostering knowledge sharing through people management practices. International Journal of Human Resource Management 16(5): 720-735.

Cabrera, A., WC. Collins, and JF. Salgado. 2006. Determinants of individual engagement in knowledge sharing. International Journal of Resource Management 17(2): 245-264. 
Chiu, CM., MH. Hsu, and ETG. Wang. 2006. Understanding knowledge sharing in virtual communities: the relationship between trust, self-efficacy, and outcome expectations. International Journal of HumanComputer Studies 65(2): 153-169.

Ciborra, C. 2002. Labyrinths of information. Oxford: Oxford University Press.

Cox, A. M., PD. Clough, and J. Marlow. 2008. Flickr: a first look at user behaviour in the context of photography as serious leisure. Information Research 13(1). URL - http://informationr.net/ir/131/paper336.html [viewed October 19, 2009].

Cronin, B. 1995. The scholar's courtesy: The role of acknowledgement in the primary communication process. London: Taylor Graham.

Daniel, BK., RA. Schwier, and GI. McCalla. 2003. Social capital in virtual learning communities and distributed communities of practice. Canadian Journal of Learning and Technology 29(3): 113-139.

Denscombe, M. 1998. The good research guide. Buckingham: Open University Press.

Ellison, NB., C. Steinfield, and C. Lampe, 2007. The benefits of Facebook “friends": social capital and college students' use of online social network sites. Journal of Computer-Mediated Communication 12(4). URL -http://jcmc.indiana.edu/vol12/issue4/ellison.html][viewed October 19, 2009].

Hall, H. 2001. Input-friendliness: motivating knowledge sharing across intranets. Journal of Information Science 27(3): 139-146.

Hall, H. 2003. Borrowed theory: applying exchange theories in information science research. Library and Information Science Research, 25(3): 287-306.

Hall, H., and B. Davison. 2007. Social software as support in hybrid learning environments: the value of the blog as a tool for reflective learning and peer support. Library and Information Science Research 29(2):163187.

Hall, H., and M. Goody, 2007. KM culture and compromise - interventions to promote knowledge sharing supported by technology in corporate environments. Journal of Information Science, 33(2): 181-188.

Hsu, C-L, and JC-C. Lin. 2008. Acceptance of blog usage: the roles of technology acceptance, social influence and knowledge sharing motivation. Information and Management 45: 65-74.

Huysman, M., and V. Wulf. 2006. IT to support knowledge sharing in communities; Towards a social capital analysis. Journal of Information Technology 21: 40-51.

Janssen, O. 2000. Job demands, perceptions of effort-reward fairness and innovative work behaviour. Occupational and Organizational Psychology 73: 287-302.

Johnson, SL., and S. Faraj. 2005. Preferential attachment and mutuality in electronic knowledge networks. IC/S 2005 Proceedings. Paper 24. URL - http://aisel.aisnet.org/icis2005/24 [viewed 6 April 2010]

Kankanhalli, A., BCY. Tan, and K-K. Wei. 2005. Contributing knowledge to electronic knowledge repositories: an empirical investigation. MIS Quarterly 29(1): 113-143.

Lakhani, KR., and E. von Hippel. 2003. How open source software works: free user-to-user assistance. Research Policy 32(6): 923-943.

Law, SP-M. and MK. Chang. 2008. Fostering knowledge exchange in online communities: a social capital building approach. ICIS 2008 Proceedings. Paper 173. URL - http://aisel.aisnet.org/icis2008/173 [viewed 6 April 2010] 
Liang, T-P., C-C. Liu, and C-H. Wu. 2008. Can social exchange theory explain individual knowledge sharing behaviour? A meta-analysis. ICIS 2008 Proceedings. Paper 171. URL http://aisel.aisnet.org/icis2008/171 [viewed 6 April 2010]

Malaby, T. 2006. Parlaying value: capital in and beyond virtual worlds. Games and culture 1(2): 141-162.

Matzat, U. 2007. Social networks and cooperation in electronic communities. Ashland, OH: Purdue University Press.

Mauss, M. (1925/1990). The gift (W. Hall, trans). New York: Norton. (Original work published 1925).

McNiven, IJ. 1998. Enmity and amity: Reconsidering stone-headed club (gabagaba) procurement and trade in Torres Strait. Oceania 69: 94-115.

Nahapiet, J., and S. Ghoshal. 1998. Social capital, intellectual capital, and the organizational advantage. Academy of Management Review 23: 242-266.

Sawyer, S., K. Eschenfelder, and R. Heckman. 2000. Knowledge markets: Cooperation among distributed technical specialists. In Knowledge management for the information professional, ed. T. Srikantaiah, and M. Koenig, 181-204. Medford, NJ.: Information Today.

Silverman, D. 1993. Interpreting qualitative data. London: Sage.

Stefanone, MA., and C-Y. Jang. 2008. Social exchange online: public conversations in the blogosphere. Proceedings of the $41^{\text {st }}$ Hawaii International Conference on System Sciences. January 7-10, 2008, Big Island, Hawaii. DOI -http://doi.ieeecomputersociety.org/10.1109/HICSS.2008.400

Tajfel, H. 1982. Social identity and intergroup behaviour. Cambridge: Cambridge University Press.

Tiwana, A., and AA. Bush. 2005. Continuance in expertise-sharing networks: a social perspective. IEEE Transactions on engineering management 52(1): 85-101.

Wasko, MM., and S. Faraj. 2005. Why should I share? Examining social capital and knowledge contribution in electronic networks of practice. MIS Quarterly 29(1): 35-57.

Watson, S., and K. Hewett. 2006. A multi-theoretical model of knowledge transfer in organizations: determinants of knowledge contribution and knowledge reuse. Journal of Management Studies 43(2): $141-173$

Willem, A., H. Scarbrough, and M. Buelens. 2008. Impact of coherent versus multiple identities on knowledge integration. Journal of Information Science 34(3): 370-386.

Williams, D., N. Ducheneaut, L. Xiong, Y. Zhang, N. Yee and E. Nickell. 2006. From tree house to barracks: The social life of guilds in World of Warcraft. Games and Culture 1(4): 338-361.

Wu, S., CS. Lin, and T-C. Lin. 2006. Exploring knowledge sharing in virtual teams: a social exchange theory perspective. Proceedings of the $39^{\text {th }}$ Hawaii International Conference on System Sciences. January 4-7, 2006, Big Island, Hawaii. DOI -http://doi.ieeecomputersociety.org/10.1109/HICSS.2006.177 